\title{
Repetisi Tindakan Allah atas Penciptaan Perempuan Menurut Kejadian 2:18-22
}

\author{
Farel Yosua Sualang \\ Sekolah Tinggi Teologi Injili Indonesia Yogyakarta \\ Korespodensi: sualangfarel@gmail.con \\ Samgar Setia Budhi \\ Sekolah Tinggi Teologi Kalimantan \\ samgarbudhi@sttkalimantan.ac.id \\ Jani \\ Sekolah Tinggi Teologi Injili Indonesia Yogyakarta \\ jannilewi@gmail.com
}

\begin{abstract}
Genesis 2 deals a lot with a description of the time, reason, manner and outcome of Genesis regarding the creation of male and female relationships, especially the second part in Genesis 2:18-25. The scope of the discussion 2:18-22 is widely discussed using contemporary issues with the lens of social, psychology and anthropology. Likewise, the issues of biblical research on its use of canonical and noncanonical texts. By using the sub-hermeneutic qualitative method: Exegesis, the author finds that God's initiative for the purpose of His creation to humans can be observed through repetion parallelism (stair parallelism) in the scope of Genesis 2:18-22 ("God said...," "God formed... ," God created..." and "God created..."). This can be observed when initiative God created a woman by observing the word image and likeness of God, so as not to emphasize the superiority and inferiority between men and women.
\end{abstract}

Keywords: genesis; equality; creation; repetition

\begin{abstract}
Abstrak
Kejadian 2 banyak membahas suatu deskripsi waktu, alasan, cara dan hasil mengenai Kejadian penciptaan hubungan laki-laki dan perempuan, khususnya bagian kedua dalam kejadian 2:18-25. Lingkup pembahasan 2:18-22 banyak dibahas dengan menggunakan isu-isu kontemporer dengan lensa sosial, psikologi, antropologi. Begitu pun, isu-isu penelitian biblika terhadap penggunaannya terhadap teks kanonik dan non-kanonik. Dengan menggunakan metode kulitatif sub-hermeneutik: Eksegesis, penulis menemukan bahwa inisiatif Allah atas tujuan ciptaanNya kepada manusia dapat diperhatikan melalui paralelisme repetisi (paralelisme bertangga) dalam lingkup Kejadian 2:18-22 ("Tuhan Allah berfirman...," "Tuhan Allah membentuk...," Tuhan Allah membuat..." dan "Tuhan Allah menciptakan..."). Ini dapat dicermati ketika inisiatif Allah menciptakan seorang perempuan dengan mencermati kata gambar dan rupa Allah, sehingga tidak menekankan superioritas dan inferioritas antara laki-laki dan perempuan.
\end{abstract}

Kata Kunci: Kejadian; kesetaraan; penciptaan; repetisi 


\section{Pendahuluan}

Kitab Kejadian merupakan kitab tentang permulaan. Kelima puluh pasalnya menggambarkan sejarah manusia dari penciptaan sampai Babel (Kej. 1-11) dan dari Abraham sampai Yusuf (Kej. 12-50). ${ }^{1}$ Sebelas pasal pertama memperkenalkan Allah sebagai pencipta dan permulaan kehidupan, dosa, hukuman, keluarga, penyembahan dan lain-lain. Pasal-pasal selanjutnya berfokus kepada kehidupan empat bapa iman: Abraham, Ishak, Yakub, Yusuf dan juga menjelaskan tokoh-tokoh yang lain.

Pada bagian awal kitab Kejadian diceritakan mengenai keberadaan mulamula alam semesta dan manusia. Ada penciptanya yaitu Allah sendiri. Allah membuat segala sesuatu dengan baik, bahkan titik puncak penciptaan Allah adalah manusia. Manusia berbeda dengan segala makhluk lainnya dalam dua hal: pertama, manusia dibuat seperti Allah menurut gambar dan rupa-Nya. Kedua, manusia diberi tugas dan tanggung jawab untuk berkuasa atas segala ciptaan-Nya yang lain. Penulis kitab Kejadian memberikan uraian khusus tentang penciptaan manusia pada pasal 1:1-2:25. Uraian kedua (Kej. 2:5-25) mengenai penciptaan merupakan perluasan dari yang pertama sebagai dasar atau tumpuannya. Uraian itu ditulis dari sudut pandang yang berbeda dan kali ini difokuskan pada manusia. Ayat 5-25 juga dipakai nama yang berbeda bagi Allah.

Kisah penciptaan awal dalam Kejadian 1:7-27 hanya menyatakan bahwa Allah menciptakan manusia, laki-laki dan perempuan, dan tidak menjelaskan secara lengkap mengenai cara kerja Allah dalam pelaksanaannya. Cerita tentang Manusia (Adam) telah dipaparkan secara lengkap pada kejadian 2:7-17. Namun begitu, pembahasan mengenai deskripsi waktu, alasan, cara dan hasil mengenai hubungan laki-laki dan perempuan banyak diterangkan dalam perkataan Tuhan pada Kejadian 2:18-22. Sejauh ini banyak penafsir yang menghubungkan interpretasi Kejadian 2:1822 kepada isu-isu kontemporer, khususnya lensa sosial, psikologis, dan antropologis. ${ }^{2}$ Menurut Estes keseluruhan Kejadian pasal dua menekankan antropologis teologis yang berkontribusi pada penyandang disabilitas dengan mengangkat 3 tema utama yaitu perwujudan, ketidaksempurnaan dan hubungan manusia sebagai suatu keterbatasan manusia dari ciptaan Tuhan. ${ }^{3}$ Nampaknya, Estes memakai lensa topikal dalam orientasinya terhadap studi disabilitas. Berbeda dengan Agana, ia menyetujui bahwa Kejadian 2:18 dan 24 tidak memberikan perintah secara khusus mengenai pernikahan. ${ }^{4}$ Agana menerapkan pendekatan analisis konteks dari narasi untuk menekankan ajaran-ajaran Alkitab yang lebih luas tentang pernikahan. Ia menemukan bahwa pengambilan bagian tubuh Adam (tulang rusuk) dapat dilihat sebagai suatu parallel atau kesejajaran dalam proses

1 Jeffrey G. Audirsch, “Book Review: Discovering Genesis: Content, Interpretation, Reception.," Biblical Theology Bulletin: Journal of Bible and Culture 48, no. 1 (2018): 41-42.

${ }^{2}$ Tammi J. Schneider, "In the Beginning and Still Today: Recent Publications on Genesis," Currents in Biblical Research 18, no. 2 (2020): 142-159.

${ }^{3}$ Joel D. Estes, "Imperfection in Paradise: Reading Genesis 2 through the Lens of Disability and a Theology of Limits," Horizons in Biblical Theology 38, no. 1 (2016): 1-21.

${ }^{4}$ Agana-Nsiire Agana, "Is Marriage for All? A Theological Reflection on the Grammar of Genesis 2:18, 24," Asia-Africa Journal of Mission and Ministry 17, no. 3 (2018): 90. 
hortikultura. ${ }^{5}$ Baden memperhatikan Kejadian 2:21-22 sebagai suatu metafora terhadap proses "pertanian" penciptaan. Ia memandang bahwa Allah dapat digambarkan sebagai "tukang kebun" Ilahi. Namun begitu, orientasi terhadap isu-isu eksegesis terhadap kritik teks atau perbandingan terjemahan Kejadian 2:18-22 juga diperhatikan oleh beberapa penafsir, seperti penelitian Chia. Ia mencoba menafsirkan dan menerjemahkan Kejadian 2:21-24 dengan menggunakan terjemahan Vulgata. Khususnya, Chia mengartikan kata ergo, cumque, replevit, vigaro dan katakata lain yang menekankan makna tentang tema kesatuan antara laki-laki dan perempuan. ${ }^{6}$ Sisi yang lain, Peterson secara konsisten menafsirkan Kejadian 2:18-22 dengan memperhatikan konteks Kejadian 1:26-28. Menurutnya interpretasi Kejadian 2:18-22 sangat menekankan pernikahan heterosesksual, khususnya penggunaan secara interteksual dalam Matius 19 dan Markus 10.7 Peterson memperhatikan isu terhadap penafsiran dari kalangan kaum Injili yang sudah mulai bergeser terhadap pernikahan sesama jenis.

Jika memperhatikan secara khusus pentingnya interpretasi Kejadian 2:18-22 sebagai suatu genre dari kisah penciptaan, maka menarik bagi peneliti untuk menerapkan suatu pendekatan eksegesis yang mendalam. Lalu, apa saja keunikan dari kesejajaran bertangga dalam Kejadian 2:18-22 yang berhubungan dengan makna rencana Allah terhadap kesatuan antara laki-laki dan perempuan? Penelitian ini bertujuan untuk menemukan bahwa peran aktif Allah atas tujuan penciptaan manusia dapat ditunjukan melalui paralelisme repetisi (paralelisme bertangga) dalam Kejadian 2:18-22 ("Tuhan Allah berfirman...," “Tuhan Allah membentuk...," Tuhan Allah membuat..." dan "Tuhan Allah menciptakan..."). Hal ini dapat diperhatikan ketika Allah menciptakan seorang perempuan dengan mencermati kata gambar dan rupa Allah, sehingga tidak menekankan superioritas dan inferioritas antara laki-laki dan perempuan.

\section{Metode Penelitian}

Artikel ini menggunakan metode kualitatif dengan pendekatan hermeneutik (Interpretative design): Eksegesis. ${ }^{8}$ Khususnya, peneliti menggunakan analisis sastra narasi (kisah penciptaan) dengan memperhatikan analisis teks-teks dari kata-kata kunci Ibrani (studi kata), tata bahasa, struktur narasi, plot, penggunaan bahasa kiasan, konteks historis dan makna teologis Kejadian 2:18-22.9 Sebagai alat bantu,

${ }^{5}$ Joel Baden, “An Unnoted Nuance in Genesis 2:21-22," Vetus Testamentum 69, no. 1 (2019): 167-172.

${ }^{6}$ Philip Suciadi Chia, "A Marriage Concept on Genesis 2:21-24 (An Analysis of Latin Vulgate)," Didaskalia 2, no. 1 (2019): 29.

${ }^{7}$ Brian Neil Peterson, “Does Genesis 2 Support Same-Sex Marriage? An Evangelical Response," Journal of the Evangelical Theological Society 60, no. 4 (2017): 681-696. Hampir sama juga ditekankan oleh Putra terhadap penggunaan Kej. 2:24 dalam Matius 19. Adi Putra, "Problematika Teks Dan Makna Matius 19: 9 Tentang Perceraian," Missio Ecclesiae 9, no. 2 (2020): 1-16.

8 Sonny Eli Zaluchu, "Strategi Penelitian Kualitatif Dan Kuantitatif Di Dalam Penelitian Agama," Evangelikal: Jurnal Teologi Injili dan Pembinaan Warga Jemaat 4, no. 1 (2020): 35. Sonny Eli Zaluchu, "Metode Penelitian Di Dalam Manuskrip Jurnal Ilmiah Keagamaan," Jurnal Teologi Berita Hidup 3, no. 2 (2021): 254.

${ }^{9}$ Grant R. Osborne, Hermeneutika Spiritual- Pengantar Komperehensip Bagi Penafsiran ALkitab (Surabaya: Momentum, 2012), 255. 
pemakaian leksikon (lexicon), buku tafsiran (commentary books), dan artikel sangat menyokong dalam riset ini.

\section{Hasil dan Pembahasan}

\section{TUHAN Allah Berfirman tentang Penolong (ay.18)}

Ayat 18 menjelaskan tentang inisiatif dari firman Allah yang menciptakan seorang penolong bagi manusia untuk mengelola dan menguasai bumi serta segala isinya. Dasar dari paralelisme bertangga ini memberikan penekanan dari Firman Allah terhadap pentingnya hubungan kebersamaan mereka (ay.18).

\section{Tidak Baik Manusia Seorang diri (ay. 18a)}

Ayat 18a memberikan suatu petunjuk atas penciptaan perempuan yang

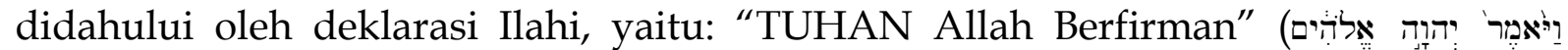
wayyōmer YHWH 'élōhîm). ${ }^{10}$ Tema tentang "penyediaan" berlanjut dalam cerita ini (konteks pasal 1 dan 2) ketika Allah menciptakan "penolong yang cocok" untuk manusia (ayat 18, 20). Keunikan dari kisah penciptaan ini adalah deklarasi Allah bahwa "tidak baik" jika manusia itu seorang diri. Klausa "lalu berkatalah Tuhan" memberikan suatu perhatian khusus tentang sifat Allah yang kreatif pada pasal 1, serta mengekspresikan perenungan Tuhan atas ciptaan-Nya yang "sangat baik." Pengamatan semacam ini menekankan pentingnya wanita dalam pikiran Allah. ${ }^{11}$ Inisiatif Ilahi memberikan suatu tahap utama dalam perikop ini. Jika memperhatikan tahapan-tahapan yang semakin meningkat pada setiap kalimat dalam ayat 18-22, maka ditemukan adanya paralelisme repetitif bahwa TUHAN Allah merupakan subjek utama yang bekerja bagi manusia untuk memberi seorang penolong. Ini mulai dari kalimat "TUHAN Allah berfirman" (ayat 18), "TUHAN Allah membentuk" (ayat 19), "TUHAN Allah yang membuat ... tidur nyenyak" (ayat 21), dan "TUHAN Allah menciptakan perempuan" (ayat 22). Tabel di bawah ini memperjelas maksud pernyataan di atas.

Tabel 1. Paralelisme Repetitif mengenai Tindakan Allah atas Penciptaan Perempuan dalam Kejadian 2:18-22

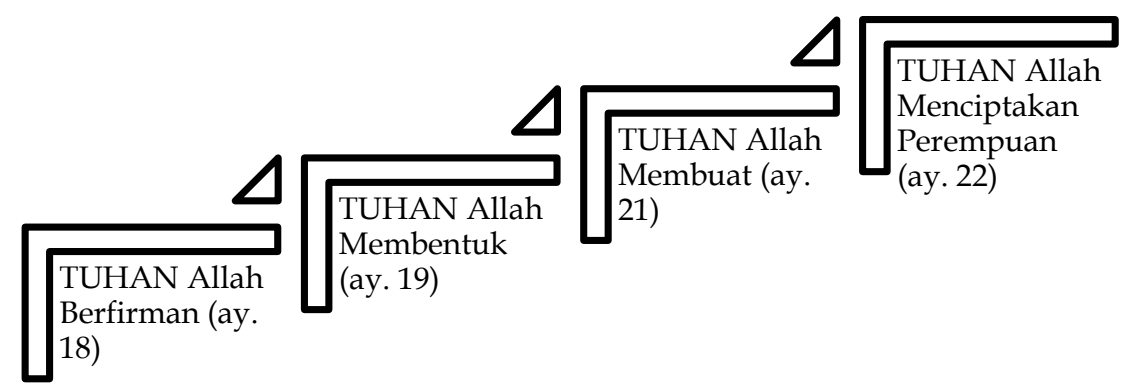

${ }^{10}$ Kompleks klausa yang sebelumnya dibangun di sekitar kutipan yang ditujukan kepada manusia. Klausa ini memulai kompleks klausa baru. Dimana proses kata kerjanya tidak memiliki penerima. Barry Bandstra, Genesis 1-11: A Handbook on The Hebrew Text (Waco, Texas: Baylor University Press, 2008), 145.

${ }^{11}$ Kenneth A. Mattews, The New American Commentary: An Exegetical and Theological Exposition of Holy Scripture Genesis 1:11-26, Vol. 1 A (Nashville: B\&H Publishing Group, 1996), 183. 
Penggunaan kata kerja di atas nampak memberikan penjelasan bahwa Allah berperan aktif atas tujuan penciptaan manusia. Hal ini dapat dilihat kembali bagaimana Allah menciptakan seorang perempuan dengan memperhatikan tujuan mula-mula diciptakan manusia pada Kejadian 1:26-28 sebagai gambar dan rupa Allah untuk menguasai bumi serta ciptaan-ciptaan yang lain. Pribadi TUHAN Allah (יהונה אלהים: YHWH 'élōhîm) yang ditekankan dalam pasal 2:18-22 memberikan suatu penegasan bahwa Allah memberikan perjanjian dan anugerah kepada Adam dan Hawa. ${ }^{12}$ Oleh sebab itu, keseluruhan pasal 2 memunculkan sebelas kali nama TUHAN (Yahweh) yang berpasangan dengan kata Elohim (Allah). Hal ini jelas menunjukkan bahwa Allah yang sama mengasihi dan memelihara Adam bagaikan anak laki-lakiNya, yang Ia ciptakan menurut gambar-Nya.

Isi dari perkataan YHWH Elohim "tidak baik kalau manusia itu seorang diri

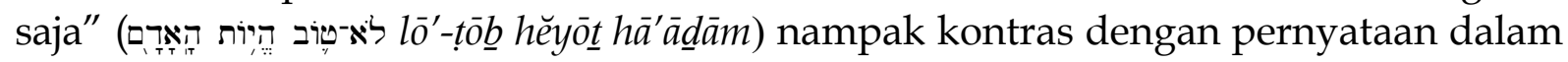
pasal 1:31, di mana setelah penciptaan selesai, Allah melihat bahwa semua yang diciptakan-Nya itu "sungguh amat baik." Konteks penciptaan dalam Kejadian 1:28 menunjukan bahwa Allah memerintahkan manusia untuk beranak cucu dan berkembang biak. Oleh sebab itu, manusia tidak bisa memenuhi perintah itu jika ia seorang diri saja. Dengan kata lain, kesendirian manusia itu mencegahnya dari menggenapi desain penciptaan dan karena itu tidak baik.13

\section{Allah Menciptakan Seorang Perempuan}

Allah berinisiatif untuk menciptakan seorang pendamping bagi manusia itu agar dapat menjalankan amanat-Nya (Kej. 1:28). Ia berfirman: “Aku akan membuat

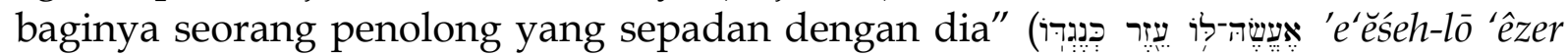
$k \partial n e \bar{g} \bar{d})$. Allah sebagai inisiator dalam penciptaan wanita yang nampak dinyatakan

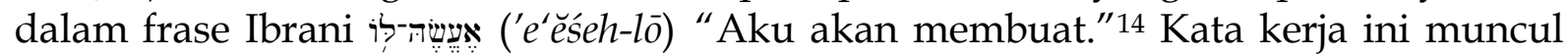
sebanyak 2527 kali dalam stem qal yang memiliki arti "membuat dan menghasilkan" (Kej. 3:21; 8:6; 1 Sam. 8:12; 2Raj. 12:12). ${ }^{15}$ Walaupun kata kerja ini dapat diartikan "menciptakan," seperti Allah "menciptakan" langit dan bumi dalam Kejadian 1:1, namun penggunaan kata Ibraninya sama sekali berbeda. Kejadian 1:1 menggunakan

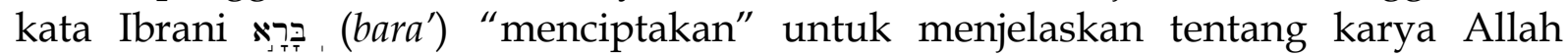
terhadap alam semesta (Kej. 2:4; 2Raj. 19:15; Yes. 37:16; 66:22 "khususnya Yesaya 4066"; Yer. 32:17; Maz. 115:15; 121:2; 124:8; 134:3; 146:6). ${ }^{16}$ Hal ini memberikan maksud mutlak terhadap penciptaan secara ex-nihilo (dari yang tidak ada). ${ }^{17}$ Perlu ditambahkan juga bahwa kata kerja ini dapat dipakai sebagai bentuk tindakan Ilahi

${ }^{12}$ Gleason L Archer, Encyclopedia of Bible Difficulties, ed. Suhadi Yeremia and Subhandiah Tjuk Kaihatu (Malang: Gandum Mas, 2004), 108.

13 Ibid.

14 Dari akar kata עָשָׁה dari kata kerja Qal Imperfek orang pertama tunggal. Deane Galbraith, "Review of John H. Walton, The Lost World of Adam and Eve : Genesis 2 - 3 and the Human Origins Debate Related Papers," Journal of the Evangelical Theological Society 58, no. 1 (2015): 168.

15 Bruce K. Waltke, Genesis: A Commentary (Grand Rapids: Zondervan Publishing, 2001), 58-59. 1994), 98-99.

${ }^{16}$ Claus Westermann, Genesis 1-11: A Continental Commentary (Minneapolis: Fortress Press, 335-337.

17 Bruce K. Waltke, “The Creation Account in Genesis 1:1-13,” Bibliotheca Sacra 13, no. 2 (1975): 
yang sama sekali baru dan ajaib. Sedangkan kata pertama sangat menekankan kepada tindakan manusia yang membuat sesuatu dan kedua, dibuat dari material yang sudah ada sebelumnya. Oleh sebab itu, penciptaan perempuan akan menemani manusia itu untuk mengikuti perspektif dalam penciptaan pertama, karena ia diambil dari material yang sudah ada, yaitu tulang manusia itu (ay. 21).

Berdasarkan pemaparan di atas, maka dapat diperhatikan bahwa desain Ilahi dideskripsikan dengan 3 (tiga) kata benda penting, yaitu: pertama, לאיאוֹ

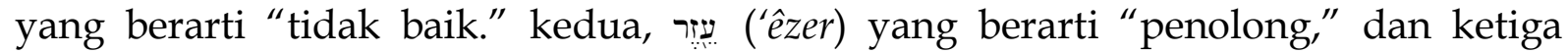

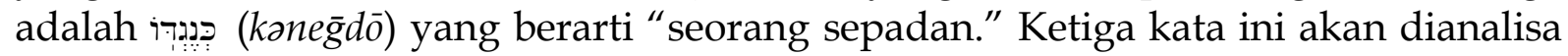
oleh penulis pada bagian di bawah ini.

\section{Tidak Baik Seorang Diri}

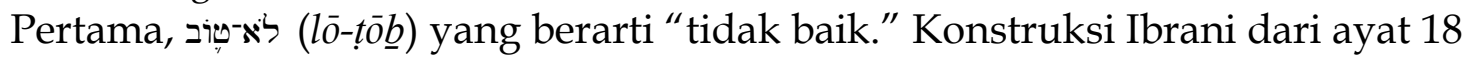
memberi penekanan terhadap frase "tidak baik" dengan menempatkannya sebagai kepala kalimat. Tuhan telah menciptakan manusia dan menyediakan lingkungan yang indah dengan pekerjaan yang terhormat, namun Tuhan memberitahukan bahwa ada sesuatu yang harus dilakukan untuk kepentingan manusia. Perhatian Tuhan merujuk pada "kesendirian" manusia itu. Memang pada awalnya tidak dinyatakan bahwa manusia itu merasa kesepian; namun pada ayat 18 sudut pandang Ilahi diberikan kepada manusia. Tuhan telah menciptakan kehidupan manusia untuk bersekutu dengan-Nya tetapi manusia diciptakan sebagai makhluk sosial, dimana ia dapat membangun hubungan dengan manusia lain. "[Manusia] tidak akan hidup sampai dia mencintai, menyerahkan dirinya kepada orang lain pada levelnya sendiri."18

Perlu diketahui bahwa frase ini adalah empatik atau frase penegasan. Pada dasarnya adalah hal yang buruk bagi manusia untuk sendirian. ${ }^{19}$ Tuhan memang menginginkan suatu pernikahan yang melibatkan keintiman dan hubungan seksual. ${ }^{20}$ Hubungan yang diperagakan menurut Allah tidak berada dalam "pengasingan" tetapi merupakan ketetapan-Nya secara mutlak. Menurut Stration, "Tuhan mengevaluasi situasi di taman Eden dalam Kejadian 2:18 dan merasa 'tidak baik' kalau manusia itu sendirian." 21 Penilaian ini mungkin mengejutkan bagi para pembaca karena di dalam Kejadian 1 nampaknya begitu sering ditemukan bahwa Tuhan menganggap berbagai aspek penciptaan 'baik' dan khusus kepada manusia itu 'sangat baik'. 'Tidak baik' di sini mungkin merupakan sinyal kemudian bahwa penciptaan belum selesai. Allah masih menganggap manusia itu seorang diri, terlepas dari konteks sebelumnya mengenai perintah Allah kepada manusia. Allah memutuskan penciptaan perempuan sebagai 'penolong atau rekannya'.

${ }^{18}$ F. Derek Kidner, Genesis, Tyndale Old Testament Comantaries (Chicago: InterVarsity Press, 2016), 21.

${ }^{19}$ N Sama, Genesis, JPS Torah Commentary 1 (Philadelphia: Jewish Publication Society, 1989),

21.

20 Waltke, Genesis: A Commentary, 88.

21 Beverly J. Stration, Out of Eden: Reading, Rhetoric, and Ideology in Genesis 2-3 (Sheffield: Sheffield Academic Press, 1995), 163. 


\section{Seorang Penolong}

Kedua, ("êzer) yang berarti "penolong." 22 Kata benda ini memiliki cara penggunaan yang berbeda-beda dalam Perjanjian Lama. Hal tersebut dibedakan dari kata benda feminim עִ עְרָה ('ezrāh) yang memiliki arti yaitu, "penolong, pendukung." 23 Kata benda ('êzer) muncul 21 kali dalam Alkitab Ibrani. Dalam delapan contoh, kata itu berarti "penolong." Contoh-contoh ini mudah diidentifikasi karena digunakan dengan ungkapan penolong, penyelamat atau dengan gagasan yang terkait lainnya. ${ }^{24}$ Penggunaan kata benda maskulin dari kata ('êxzer) memang menunjukkan bahwa penulis Kejadian 2:18 memilih istilah netral untuk menghindari ide bahwa wanita hanya sebagai "penolong/pembantu" atau "pendukung" bagi manusia.

Terjemahan "aid" memang tidak tepat dengan istilah aslinya. ${ }^{25}$ Terjemahan dari KJV yaitu "help meet" terdiri dari dua kata dalam bahasa Inggris. Istilah "meet" adalah istilah kuno (archaism), yang berarti "diadaptasi" atau "cocok" 26 serta memiliki relasi sedikit dengan istilah "penolong" yang merupakan kata "help meet for him" yang telah keliru dibaca sebagai satu kata. Maka dari pernyataan di atas, frase "perempuan sebagai penolong" memiliki arti bahwa dia adalah jodoh untuk membantu tugas-tugas suaminya. ${ }^{27}$ Pengertian inilah yang memberikan suatu kesalahan terhadap ketidaktahuan yang aneh dari bahasa Inggris.

Perlu diketahui narasi mengenai taman Eden bergerak melampaui penilaian awal dengan menentukan perbedaan fungsional yang ada di antara laki-laki dan wanita. Hawa disebut "penolong" Adam (ي ي 'êzzer) yang menunjukkan identifikasi mengenai peran secara integral. Pertanyaannya adalah dengan cara apa Hawa akan menjadi "penolong" bagi Adam? Seperti penjelasan penulis sebelumnya, istilah ini berarti "menolong" dalam arti bantuan ataupun dukungan (Ul. 33:7; Yos. 1:14; Yes. 30:5; Dan. 11:34), dimana biasanya juga digunakan untuk membantu umat-Nya menghadapi musuh (Maz 20: 2; 121: 1-2; 124: 8). Musa berbicara tentang Allah sebagai "penolong" yang membebaskannya dari Firaun (Kel 18: 4), dan itu sering dikaitkan dengan "perisai" dalam menggambarkan perawatan perlindungan Allah terhadap umat-Nya (Ul. 33:29; Maz. 33:20; 115:9-11; Band. Maz. 70:6.).

Tidak ada pengertian secara linguistik atau dari konteks perikop ini bahwa wanita itu adalah orang yang lebih rendah dari laki-laki karena memiliki peran yang berbeda (perhatikan juga konteks dalam 2:23). Dalam kasus-kasus yang ditemukan pada Alkitab, "penolong" merupakan "mitra" yang sangat diperlukan untuk

${ }^{22} \mathrm{G}$ Johannes Botterweck, Helmer Ringgren, and Heinz-Josef Fabry, Theological Dictionary of The Old Testament (Michigan: William B. Eerdman's, 1998), 175. Bandstra, Genesis 1-11: A Handbook on The Hebrew Text, 147. David Freedman, "A Power Equal to Man: Translation of Woman as a 'Fit Helpmate' for Man Is Questioned," Biblical Archeology Review 9, no. 1 (1983): 56-58.

${ }^{23}$ William L Holladay, "עזר" dalam Concise Hebrew and Aramic Lexicon (Michigan: Wm. B. Eerdmans Publishing, 1971), 270.

${ }^{24}$ Freedman, "A Power Equal to Man: Translation of Woman as a 'Fit Helpmate' for Man Is Questioned," 56-58.

${ }^{25}$ E. A. Speiser, Genesis "Anchor Bible" (Garden City: Doubleday, 1964), 15.

${ }^{26}$ G. R. Driver, "Theological and Philological Problems in the Old Testament," The Journal of Theological Studies 47, no. 1 (1946): 161-162.

${ }^{27}$ Grecetinovitria Merliana Butar-butar, “Ezer Kenegdo: Eksistensi Perempuan Dan Perannya Dalam Keluarga," Jurnal Teologi Cultivation 4, no. 1 (2020): 50-51. 
mencapai tugas Ilahi. "Penolong" sebagaimana yang telah diperhatikan oleh penulis dari penggunaan Perjanjian Lama, memainkan bagian integral. Dalam hal ini, apa yang kurang dari laki-laki tersebut mengenai kelangsungan hidup dan kesuksesan manusia itu sendiri, wanita tersebut berhasil melakukannya. ${ }^{28}$ Seperti yang dikatakan Paulus secara singkat, "dan laki-laki tidak diciptakan karena perempuan, tetapi perempuan diciptakan karena laki-laki" (1 Kor 11:9). Wanita itu memungkinkan bagi pria untuk mencapai berkat yang sebaliknya tidak dapat dia lakukan secara "sendirian." Begitu juga sebaliknya, wanita itu tidak dapat mencapai hal-hal tersebut selain dari peran laki-laki.

Jika memperhatikan pernyataan-pernyataan di atas, maka wanita adalah penyedia "bantuan" Ilahi kepada laki-laki, dimana Tuhan akan memberkati mereka ketika mencapai mandat yang telah diberikanNya. Kata ('ểzer) dalam 2:18 memberikan antisipasi dengan cara yang tidak terduga dimana Hawa akan menjadi "penolong" bagi suaminya. Dia akan berperan dalam menyediakan keselamatan bagi Adam yang jatuh oleh "keturunannya" yang akan mengalahkan ular (3:15). Bahasa Ibrani zera ("seed") mungkin merupakan permainan kata dengan bentuk suara yang hampir sama dengan 'êzer ("penolong"). ${ }^{29}$ Sejak Tuhan mengatakan bahwa perempuan itu menjalankan peran sebagai "penolong," maka istilah ini tidak mengurangi derajatnya atas peran yang dilakukannya. Jika pun ada, maka itu berlaku atas tokoh yang lain dimana nuansa ilahi dari istilah "penolong" dalam Pentateukh memberikan martabat secara khusus (U1 33: 7, 26, 29).

\section{Seorang Sepadan}

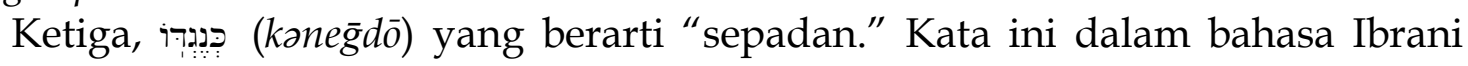
dapat berarti "seperti rekannya" (like his counterpart) atau "seperti di depannya," khususnya ayat 18 menunjukan hubungan yang cocok (corresponding) antara pria dan wanita. ${ }^{30}$ Fokusnya adalah pada kesetaraan keduanya sebagai suatu konstitusi keluarga yang diciptakan Tuhan. ${ }^{31}$ Laki-laki dan wanita berbagi dalam kesamaan sebagai "manusia" yang tidak dapat ditemukan pada ciptaan lainnya. Dalam semua hal, wanita berbagi dalam ciri-ciri kepribadian yang sama dengan pria, sekalipun memiliki perbedaan dari sisi seksualitas. Oleh sebab itu, Kejadian 1:26-28 menunjukkan bahwa laki-laki dan wanita merupakan gambar Allah yang memiliki kedudukan yang sama di hadapan Allah. ${ }^{32}$

Hawa adalah mitra yang pantas dan tepat untuk mendampingi Adam karena perempuan itu diciptakan oleh Allah sebagai penolong yang cocok dan sesuai

\footnotetext{
${ }^{28}$ Heri Lim, "Memahami Kisah Penciptaan Manusia dan Alam Semesta: Sebuah Pendekatan Literer Terhadap Kejadian 1-2,” Jurnal Amanat Agung 14, no. 2 (2020): 201-202. Antonius Steven Un, “Alkitab Menentang Pernikahan Sesama Jenis Kelamin,” Verbum Christi 4, no. 1 (2017): 3-4.

${ }^{29}$ Mattews, The New American Commentary: An Exegetical and Theological Exposition of Holy Scripture Genesis 1:11-26, Vol. 1A.

30 Botterweck, Ringgren, and Fabry, Theological Dictionary of The Old Testament, 175. Butarbutar, “Ezer Kenegdo: Eksistensi Perempuan Dan Perannya Dalam Keluarga," 50-51.

${ }^{31}$ Ruwi Hastuti, "Pendidikan Agama Kristen Dalam Keluarga Sebagai Pusat Bermisi," Jurnal Antusias 2, no. 4 (2018): 57.

32 Waltke, Genesis: A Commentary, 88. Meredith G. Kline, “Kejadian,” dalam Tafsiran Alkitab Masa Kini, Jil. 1 (Jakarta: Yayasan Komunikasi Bina Kasih, 1982), 84.
} 
dengan laki-laki. ${ }^{33}$ Pasal 1 menjelaskan bahwa pria dan wanita diciptakan "menurut

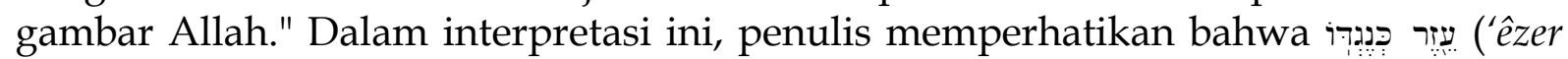
kəne $\bar{g} d \bar{o})$ memberikan fungsi sastra dari dua frasa dalam Kejadian 1 - "dalam gambar Allah" (1:26) dan "pria dan wanita yang diciptakan-Nya" (1:27). Namun dari sisi lain, jika memperhatikan secara paralelisme antitesis antara Kejadian 2:18-25 dan 3:6a-7, maka "kesetaraan" juga bisa diperhatikan dalam konteks hukuman yang sudah muncul dalam Kejadian 3. Hukuman terhadap Adam dan Hawa karena mereka telah mendurhakai Allah dan memakan buah pengetahuan yang baik dan jahat. Kesetaraan hukuman ini dapat dilihat dari tabel berikut:

Tabel 2. Kesetaraan Hukuman Adam dan Hawa dalam Kejadian 3

\begin{tabular}{|l|l|l|l|l|}
\hline Tokoh & Peran & Sikap yang baru & Pasangan & \multicolumn{1}{|c|}{ Hukuman/konsekuensi } \\
\hline Adam & Petani & Bekerja keras & Bumi & $\begin{array}{l}\text { semak duri dan rumput duri yang akan } \\
\text { dihasilkannya, dan tumbuh-tumbuhan } \\
\text { di padang akan menjadi makanannya. } \\
(3: 18)\end{array}$ \\
\hline Hawa & $\begin{array}{l}\text { Mengandung } \\
\text { Anak }\end{array}$ & Sakit/kesakitan & Adam & $\begin{array}{l}\text { Hawa akan berahi kepada suaminya dan } \\
\text { ia akan berkuasa atasnya. (3:16) }\end{array}$ \\
\hline
\end{tabular}

Seperti yang dijelaskan sebelumnya, tampaknya ada unsur kesejajaran dalam Kejadian 2:25-3:7, namun paralelisme terlihat secara antitesis pada Kejadian 3:8-24. Setelah Allah mempertanyakan Adam tentang peristiwa yang telah terjadi, ia hanya memikirkan dirinya sendiri. Adam dimintai pertanggungjawaban atas dosa yang dibuat Hawa (Kej. 3:9-11), ia juga diberi penjelasan oleh Allah mengenai penghukuman yang menimpah mereka. Ketika keadaan menjadi sulit, Adam menyalahkan Hawa atas tindakannya. Wanita itu tidak mendukung kisah yang dijabarkan oleh Adam, dan ia juga tidak mengkonfirmasi kisah laki-laki tersebut. Nampaknya, kesepadanan atau mutualitas antara keduanya telah menghilang, sekalipun kemiripan secara fundamental (fundamental likeness) masih ada antara Adam dan Hawa. ${ }^{34}$

\section{Tuhan Allah Membentuk Semua Spesies Binatang (Ay. 19-20)}

Menurut Kejadian 1, penciptaan terhadap semua jenis makhluk hidup yang ada di darat, air dan udara telah terjadi pada hari kelima dan keenam. Pada peningkatan selanjutnya, ayat 19 dan 20 merupakan pengulangan secara detail untuk menjelaskan hubungan manusia dan binatang, secara khusus peran manusia dalam pemberian nama kepada semua spesies yang diciptakan.

Tuhan Allah Membentuk Semua Spesies Binatang dari Tanah (ay.19a)

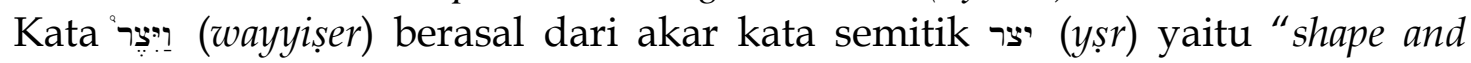
form," (diterjemahkan dalam Bahasa Indonesia sebagai kata kerja "membentuk"). Dalam Semitik Barat (Ugaritik), kata ini merupakan kata benda yang diartikan

${ }^{33}$ Ludwig Koehler, Old Testament Theology (Philadelphia: Westminster John Knox Press, 1957), 246, 103. Juliman Harefa, “Makna Allah Pencipta Manusia Dan Problematika Arti Kata 'Kita' Di Dalam Kejadian 1:26-27," EPIGRAPHE: Jurnal Teologi dan Pelayanan Kristiani 3, no. 2 (2019): 111-113.

${ }^{34}$ Lina Gunawan, "Kesetaraan Dan Perbedaan Laki-Laki Dan Perempuan: Kritik Terhadap Gerakan Feminisme," Societas 3, no. 2 (2016): 306. 
sebagai "potter" (pembuat pot). ${ }^{35}$ Kata kerja ini juga berparalelisme secara sinonim dengan kata (מד רָרא (bara) yang diartikan sebagai kata kerja "menciptakan" atau "membuat" dalam beberapa bagian, dimana orientasi pengertian utamanya adalah pada membentuk atau membuat objek yang terlihat. ${ }^{36}$ Namun begitu, jika memperhatikan pengertian secara etimologinya, maka kata ini dapat berarti sebagai suatu bagian yang menunjukan bentuk-bentuk keahlian. Dalam hubungannya dengan Kejadian 2:19, penggunaan kata yāṣar menunjukkan bahwa peristiwa penciptaan memiliki peran ataupun makna yang khusus, yaitu tindakan Tuhan yang membentuk manusia (Kej. 2:7), binatang di hutan dan burung di udara dari tanah. ${ }^{37}$

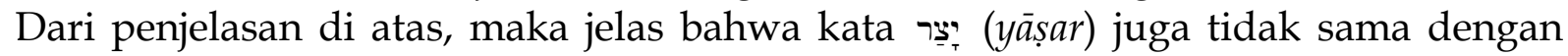

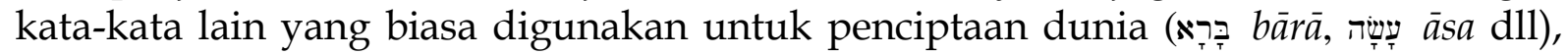
dimana kata ini hanya terbatas pada tindakan penciptaan tertentu. ${ }^{38}$

Jika memperhatikan pada konteks ayat sebelum (ay.7) dan ayat sesudahnya (ay.19), maka bahasa deskriptif dari ciptaan binatang ini "menggemakan" suatu petunjuk terhadap ciptaan manusia pada ayat ketujuh. Tuhan "membentuk" baik manusia maupun binatang atau hewan dari bahan yang sama yaitu tanah, oleh sebab itu keduanya dikatakan "makhluk hidup." 39 Namun begitu, penciptaan terhadap perempuan adalah hal yang unik. Penekanan terhadap pengambilan sumber "salah satu rusuk" dari Adam (manusia) itu sendiri, menunjukan bahwa adanya perbedaan yang sangat mendasar antara penciptaan Hawa dan binatang. Oleh sebab itu, Tuhan menciptakan Adam sebagai manusia pertama lalu mendapatkan wanita dari tulang rusuknya untuk memastikan bahwa dia setara dengan dirinya dalam substansi, kesepadanan, serta menjaga kesatuan keluarga manusia sebagai institusi pertama di dunia. ${ }^{40}$ Dengan demikian, mereka menikmati suatu persatuan terlepas dari perbedaan seksual mereka, dan adanya suatu ketergantungan dimana secara eksplisit dijelaskan dalam konteks selanjutnya sebagai "satu daging" (ayat 24).

Kejadian 2:19 telah menunjukkan bahwa Allah telah membentuk perempuan dan hewan dari tanah, namun dari argumentasi di paragraf sebelumnya menunjukan bahwa "asa" dibentuk antara mereka memiliki perbedaan yang sangat signifikan. Hal tersebut jelas tidak menampakkan suatu kesetaraan antara keduanya.

35 G Johannes Botterweck and Helmer Ringgren, Theological Dictionary of The Old Testament, Vol. VI (1990: William B. Eerdmans, 1990), 258. Hulisani Ramantswana, "Humanity Not Pronounced Good: A Re-Reading of Genesis 1:26-31 in Dialogue with Genesis 2-3," Old Testament Essays 26, no. 2 (2013): 437.

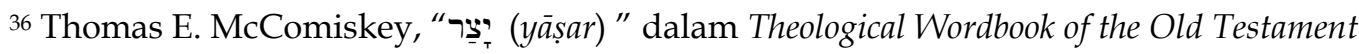
(Chicago: The Moody Bible Institute, 1981), 898.

37 Botterweck and Helmer Ringgren, Theological Dictionary of The Old Testament, Vol. VI, 261. Dana M. Pike, “The Latter-Day Saint Reimaging of 'the Breath of Life' (Genesis 2:7)," Byu Studies 56, no. 2 (2017): 73. 1997), 504.

38Willem A Vangemeren, New Intertional Dictionary of Old Testament and Exegesis (Michigan,

39 V. P. Hamilton, The Book of Genesis: Chapter 1-17 (Grand Rapids: Eerdmans Publishing, 1990), 179.

40 Joko Santoso, "Penerapan Pondasi Keluarga Bagi Generasi Penerus," Jurnal Ilmiah Religiosity Entity Humanity (JIREH) 2, no. 2 (2020): 173. Yakub Hendrawan Perangin-angin and Tri Astuti Yeniretnowati, "Keluarga Yang Sehat Dan Kuat Sebagai Profil Keluarga Kristiani," Discreet: Journal Didache of Christian Education 1, no. 1 (2021): 3. 
Allah memberikan kepada manusia untuk menguasai segala makhluk ini ("segala

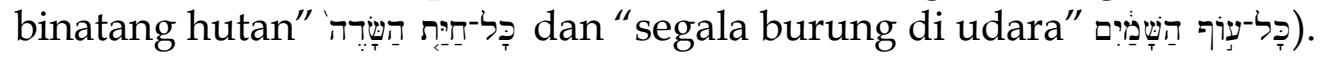

\section{Tuhan Allah Membawa Semua Spesies Binatang kepada Adam}

Setelah Allah menciptakan semua binatang di hutan dan segala burung di udara, kejadian selanjutnya adalah "dibawaNyalah semuanya kepada manusia

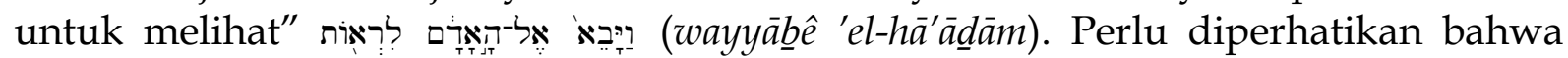
pemakaian kata kerja hiphil dari ריבָ (yābêe "membawa" berasal dari akar kata Ibrani yaitu בוּא $\left(b o^{\prime}\right)$ yang menjadi kata kerja keempat dan sering muncul dalam Perjanjian Lama. Kata kerja ini digunakan 2570 kali yang digunakan sebagian besar dengan arti "go, arrive, enter a hosue," serta bersinonim dengan kata halak "pergi," namun juga berantonim dengan kata yasa "pergi keluar." 41 Jika penulis memperhatikan secara teologis, maka kata kerja bo muncul dalam arti yang bervariasi namun konteks akan menentukan artinya.

Kata "mendatangkan" (stem hiphil) memberikan suatu penekanan bahwa Ia yang "mengakibatkan" atau "menyebabkan" semua binatang datang kepada Adam. Oleh sebab itu, kata ini mengacu kepada tindakan Ilahi yang menggerakkan segala makhluk untuk menghadap kepada Adam. Dengan kata lain, hewan dan burung diarahkan pada Adam oleh Allah untuk memberikan suatu nama atas spesies mereka. Inilah yang menjadi tanggung jawab dari Adam. Menurut penulis, ada 2 (dua) tujuan mengenai Maksud Allah mendatangkan segala binatang itu:

\section{Adam Melihat Semua Binatang}

Maksud mendatangkan semua binatang ini kepada Adam dinyatakan dalam penggunaan preposisi ? yang berarti "untuk" menyatakan maksud atau tujuan.

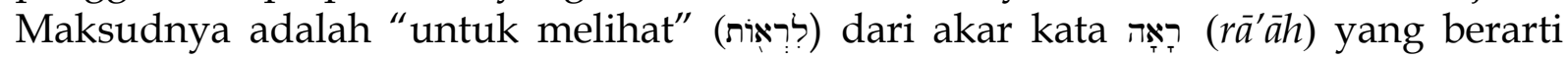
"menemui, melihat dan memeriksa."42 Memang kata רָָ (rā'āh) dapat digunakan dalam pengertiannya sebagai kata kerja "memahami," "mengamati," atau "merasakan" yang menunjukan suatu karakter dari hewan-hewan tersebut agar ia dapat memberikan nama atas dasar tersebut. ${ }^{43}$ Adam diberikan tugas oleh Allah dengan melalui proses pengamatannya untuk menamakan masing-masing spesies hewan. Oleh sebab itu, ini merupakan mandat Allah kepada manusia yang diberikan otoritas atas makhluk hidup yang lain. Dengan cara inilah, Adam tetap taat kepada kehendak Allah sebagai cermin dari gambar dan rupa Allah dengan memerintah kepada makhluk hidup yang lain, serta memberikan ketertiban atas tatanan yang teratur dalam taman Eden. ${ }^{4}$

${ }^{41}$ Elmer A. Martens, "고 $b o$ " dalam Theological Wordbook of the Old Testament (Chicago: The Moody Bible Institute, 2003), 212.

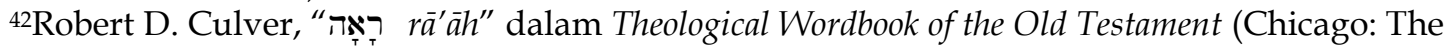
Moody Bible Institute, 2003), 295.

${ }^{43}$ Koehler and Baumgartner, Lexicon in Veteris Testamenti Libros, 19.

${ }^{44}$ Martus Adinugraha Maleachi and Hendra Yohanes, "Kehadiran Tuhan Di Tengah UmatNya: Dari Penciptaan Ke Penciptaan Yang Baru," Veritas: Jurnal Teologi dan Pelayanan 19, no. 1 (2020): 14. 


\section{Adam Menamai Semua Binatang (ay. 19b-20)}

Bagian ini dapat diperhatikan melalui kata Ibrani " "???: yiqrā' ("ia menamainya") dimana secara literal dapat berarti sebagai "ia akan memanggil mereka." ${ }^{45}$ Adam menjalankan kekuasaannya atas mereka. Tindakan Allah memberi nama $(1: 5,8,10)$ terhadap habitat makhluk itu diterapkan oleh manusia sebagai proses pemberian nama-nama (Makhluk hidup itu diberikan nama sesuai dengan 3 pengelompokan habitat yaitu, darat, laut dan udara) atas makhluk-makhluk tersebut. ${ }^{46}$ Dengan kata lain, Adam merupakan pemimpin untuk menguasai dan mengelola makhluk hidup lainnya, serta melaksanakan mandat budaya yang diberikan oleh Allah sendiri (Kej. 1:26). ${ }^{47}$ Pernyataan di atas mengangkat status manusia sebagai karya ciptaan Allah yang terbesar. Hal ini juga memperlihatkan bahwa konteks penciptaan memberikan status manusia sebagai puncak daripada hewan-hewan dan tumbuhan yang lain, namun lebih rendah dari makhluk surgawi.

Kata kerja qārā (di sisi lain dapat diartikan sebagai "ia menyebut" atau "ia memberi nama") menjelaskan bahwa manusia diberikan kemampuan berbahasa. Kata ini secara tersirat diartikan bahwa manusia dapat menempatkan gagasangagasan terhadap mandat yang diberikannya. Oleh sebab itu, manusia merupakan wakil Allah yang berfungsi untuk mewakili kekuasaan atas hewan-hewan dan tumbuhan-tumbuhan (Kej. 2:19-20; band. 1:28). ${ }^{48}$ Menurut Clarke, tindakan itu menjelaskan tentang kekuatan komprehensif pikiran penciptanya yang telah dikenakan kepada Adam. ${ }^{49}$ Hal ini juga disampaikan oleh Jamieson, "kekuatan pemahaman dan kecerdasan yang supranatural diperbesar untuk mengetahui karakter, kebiasaan dan penggunaan dari setiap spesies yang dibawa kepadanya." 50

\section{TUHAN Allah membuat Perempuan (ay. 21-22)}

Penciptaan Perempuan memberikan suatu kronologis dalam sejarah umat manusia dengan penciptaan Adam. Hal ini sangat nampak ketika urutan-urutan penciptaan dijelaskan secara spesifik dalam Kejadian 1:27. Penciptaan binatang dan burung terhubung dengan penciptaan Adam juga nampak dalam ayat 19. Hal ini terbukti adanya imperfek waw konsekutif yang merupakan kesinambungan dengan rencana penciptaan yang diberikan dalam Kejadian 1 . Pada puncak dari paralelisme repetisi ini, penulis kitab hendak menjelaskan hubungan antara manusia (tanggung jawabnya) dengan binatang, sehingga gaya terhadap kisah penciptaan ini mengungkapkan suatu pikiran bahwa: "Tuhan membawa Adam segala binatang yang dibentuk-Nya itu." "Kesinambungan ataupun urutan-urutan" penciptaan perempuan nampak pada penggunaan konjungsi ? waw sebanyak empat kali pada

45 Brown, Driver, and Briggs, A Hebrew And English Lexicon of the Old Testament, 659.

46 Theodore Hiebert, "Retranslating Genesis 1-2: Reconnecting Biblical Thought and Contemporary Experience," The Bible Translator 70, no. 3 (2019): 270.

47 Bruce K. Waltke, “The Role of Women in the Bible," Crux 31, no. 1 (1995): 29-40.

48 Allen P. Ross, "Genesis," in The Bible Knowledge Commentary (Illinois: Victor Books, 1985), 31.

${ }^{49}$ Adam Clarke, Adam Clarke's Commentary on the Old Testament (New York: Abingdon Press, 1999), 101.

${ }^{50}$ Robert Jamieson, "The First Book of Moses, Called Genesis," in Jamieson-Faussett-Brown Commentary on the Whole Bible (Harrington: Delmarva Publications, 2013), 17. 
setiap kata kerja dalam ayat 21 ini, dimana berfungsi sebagai penjelasan yang terkait pada urutan ide atau gagasan pokok dalam sebuah cerita kisah penciptaan.

\section{Ia Membuat Adam Tidur Nyenyak (ay. 21a)}

Kisah penciptaan perempuan dalam Kejadian 2:21-22 memberikan suatu simpulan pada penciptaan manusia. Allah menunjukkan inisiatifnya sebagai pribadi yang aktif untuk menciptakan perempuan sebagaimana dalam penciptaan laki-laki. Hal ini nampak ketika kisah penciptaan mengindikasikan suatu metode untuk menciptakan perempuan yang mana ia adalah suatu ciptaan istimewa di hadapan Allah. Perempuan ini diciptakan dari pengambilan salah satu organ tubuh (salah satu tulang rusuk) Adam melalui tindakan "pembedahan" yang dilakukan oleh Allah. Ayat 21a memberikan suatu bukti tahap awal dengan pernyataan, "Tuhan Allah membuat manusia itu tidur nyenyak" תֵา (tardêmāh) yang diterjemahkan sebagai "tidur nyenyak (deep sleep), mengantuk (sleepiness), lesu (lethargy)."51 "Tidur nyenyak" (tardêmāh) yang dialami Adam merupakan cara awal terhadap tindakan Allah secara eksklusif, bahkan Adam tidak sadar terhadap apa yang dilakukan oleh Allah. Kata "Tidur" menyimpan suatu misteri terhadap Adam dan selanjutnya memberikan suatu kejutan terhadap hadirnya perempuan yang ada di hadapannya. "Tidur nyenyak" biasanya digunakan untuk tidur malam (Ayub 4:13; 33:15; Ams. 19:15), tetapi di sini adalah pekerjaan istimewa Allah seperti halnya dengan Abraham tertidur (15:12; lih 1 Sam. 26:12 dan gambar menggunakan Yes. 29:10 dengan Rom.11:8). Akar verbalnya diturunkan dari kata rādam yang menggambarkan tidur Yunus, dimana ia tidak terganggu bahkan oleh laut yang menderu dan menghantam kapalnya, serta terikat di Tarsis ( Yunus 1: 5-6). ${ }^{52}$ Semua teks-teks di atas menjelaskan mengenai "tidur nyenyak" sebagai campur tangan ilahi. Oleh sebab itu, Allah yang menyebabkan tidur tersebut.

Dari pemaparan paragraf di atas, ayat 21a menekankan secara tegas bahwa manusia tidak memiliki bagian apapun dalam penciptaan perempuan ini. Dia juga nampak tidak berpartisipasi pada penciptaannya. ${ }^{53}$ Artinya bahwa tidak ada perbedaan tersirat antara laki-laki dan perempuan. Perempuan pada hakekatnya sama dengan laki-laki, yaitu ia datang dari tangan sang Pencipta seperti halnya penciptaan Adam.

\section{Ia Mengambil Salah Satu Tulang Rusuknya (ay. 21b)}

Kejadian 2:21 melengkapi pernyataan 1:27. Allah menciptakan laki-laki sebagai penduduk bumi yang diciptakan pertama. Sebagaimana laki-laki "diambil" dari bumi $(3: 19,23)$, demikian pula perempuan itu "diambil" dari laki-laki. Pada saat

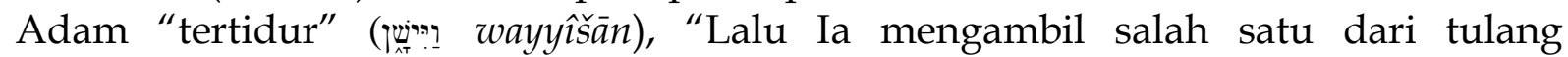

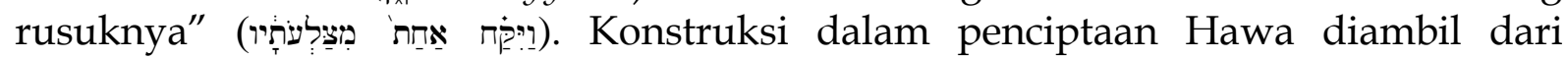

${ }^{51}$ Holladay, Concise Hebrew and Aramic Lexicon, 395.

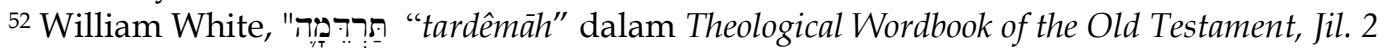
(Chicago: The Moody Bible Institute, 2003), 2123.

53 J. G. Thomson, “The New American Commentary," Vetus Testamentum 5, no. 2 (1955): 421435. 


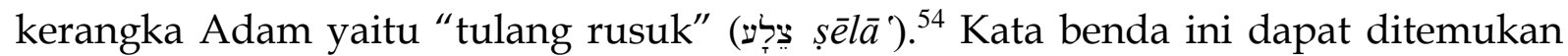
39 kali kemunculannya dalam Perjanjian Lama. Terjemahan șe $\bar{l} \bar{a}^{\prime}$ juga banyak diterjemahkan sebagai "sisi ataupun sudut." Satu kali untuk menjelaskan tentang manusia (Kej. 2:21), satu kali untuk sisi atau lereng bukit (2 Sam. 16:13; BDB), serta menjelaskan tentang arsitektur pada "sisi-sisi tabut perjanjian" (Kel. 25:12-14; 37:3, 5). ${ }^{55}$ Konteks Perjanjian Lama, kata șelā" hanya diterjemahkan sebagai "tulang rusuk" dalam Kejadian 2:21.56 "Tulang Rusuk" memang diambil dari Adam untuk menjelaskan natur manusia dalam hubungannya antara satu sama lainnya. ${ }^{57}$ Pemakaian kata ini menegaskan bahwa manusia bukan dari hasil teori apapun. ${ }^{58}$ Pengambilan tulang rusuk dari Adam memberikan suatu penekanan bahwa Hawa sebagai mitra penolongnya (helper-counterpart) dan jiwa perempuan itu terikat dengannya dalam kesepadanan, ${ }^{59}$ sehingga laki-laki dan perempuan mempunyai tanggung jawab untuk menguasai segala binatang dan tunduk di hadapan Allah.

\section{Ia Menutup Tempat itu Dengan Daging (ay. 21c)}

Tahap selanjutnya adalah menutup celah yang telah dibuat dengan daging, dimana dimasukan ke dalam tempat tulang rusuk. ${ }^{60}$ Wanita itu diciptakan bukan dari debu tanah, tapi dari tulang rusuk Adam. Ia dibentuk untuk kesatuan yang tidak terpisahkan dan persekutuan hidup dengan laki-laki itu dan modus penciptaannya adalah untuk meletakkan dasar sebenarnya bagi moral tata cara pernikahan.

\section{Ia Membawa Perempuan itu kepada Adam (ay. 22)}

Dari materi yang diambil, Tuhan "membangun" (banah, "to make, to build; to construct") perempuan. Kata ini biasanya dipakai berkaitan dengan seni kerajinan atau seni pahatan. Kata tersebut menekankan tentang Allah membentuk perempuan itu dengan keindahan yang menakjubkan. Hal ini jauh berbeda dari ciptaan Allah yang dilakukan melalui Firman dalam Kejadian 1. Tetapi sama sekali tidak mengherankan bahwa dalam konteks Kejadian 2, aktifitas penciptaan dilakukan dengan "tangan-Nya" sendiri (lih. ay 4b., 7, 8, 19). Hasil tindakan ini untuk pertama kalinya dalam Kejadian 2, jenis kelamin tertentu dikaitkan dengan istilah yang digunakan. ${ }^{61}$

Sebelumnya, manusia selalu disebut sebagai אָָ (adam) yang menunjukkan hubungan "nya" kepada 'damah, tanah dari mana "dia" dibuat. Tidak ada aspek gender dalam hal itu. Penggunaan (issah) memperkenalkan aspek itu untuk menunjukkan perbedaan manusia pertama: meskipun diambil dari materi אָָָ (adam),

54 Junius Halawa, "Pastoral Konseling Psikologi Alkitabiah Seks Sebelum Menikah," Missio Eclesiae 7, no. 2 (2018): 297.

55 Hamilton, The Book of Genesis: Chapter 1-17, 323.

56 Driver, "Theological and Philological Problems in the Old Testament," 161-162.

57 Westermann, Genesis 1-11: A Continental Commentary, 314.

58 Hamilton, The Book of Genesis: Chapter 1-17, 314.

59 Stration, Out of Eden: Reading, Rhetoric, and Ideology in Genesis 2-3, 103.

${ }^{60}$ C F Keil and F Delitzsch, Commentary on Genesis, Reprint (Grand Rapids: Eerdmans, 2000),

90.

${ }^{61}$ Henning Alexander, "Males and Females As Equals in Melanesia (An Exegesis of Genesis 2:18-25)," Melanesian Journal of Theology 20, no. 1 (2004): 65. 
perempuan tidak hanya berbeda dengan (adam), tetapi berbeda dalam beberapa cara, fungsi dan mandiri darinya. Ini menegaskan temuan di atas tentang ayat 21 dan dikembangkan lebih lanjut dalam ayat 23.62

Setelah Allah "membangun" perempuan tersebut dari rusuk yang diambil-

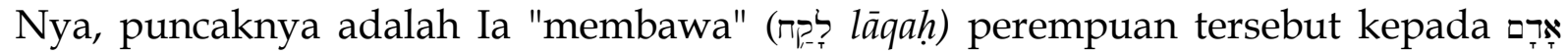
(adam) seperti sebelumnya. Semua binatang "dibawa" kepadanya (ay. 19) agar ia menamai mereka. Sekali lagi, tindakan aktif Tuhan dinyatakan dalam kata kerja ini.

\section{Implikasi}

Berdasarkan pembahasan di atas, ada beberapa implikasi yang bisa diambil dari paralelisme repetisi Kejadian 2:18-22. Pertama, Allah memiliki dan mempunyai rencana atas hidup manusia. Allah yang berinisiatif memperhatikan kesendirian manusia, merencanakan seorang penolong, membuat manusia tidur nyenyak, mengambil salah satu rusuknya dan menciptakan perempuan. Hal ini mengingatkan orang percaya agar senantiasa berserah dan bersandar kepada Allah serta mempercayai Dia dalam hidup ini. Allah tahu keberadaan orang percaya dan Dia tahu yang terbaik bagi umat-Nya.

Kedua, Allah tidak menghendaki kesendirian manusia. Kesendirian manusia adalah konsep yang tidak baik bagi Allah. Oleh sebab itu, Allah menciptakan perempuan bagi laki-laki melalui tulang rusuknya. Allah menghendaki agar manusia berpasang-pasangan dan pasangan itu adalah antara laki-laki dan perempuan, bukan laki-laki dengan laki-laki atau perempuan dengan perempuan. Dengan kata lain, Allah tidak menghendaki praktek-praktek penyimpangan seksual seperti homoseksualitas. Penghukuman atas Sodom dan Gomora mengingatkan akan bahaya dosa penyimpangan seksual ini. Gereja diingatkan agar teguh berdiri diatas pengajaran yang benar tentang hal seksualitas ini.

Ketiga, Allah menciptakan perempuan sebagai penolong yang sepadan bagi laki-laki dalam melaksanakan tugas yang Allah percayakan kepada mereka, yaitu untuk memenuhi bumi dan berkuasa atasnya. Sebagai penolong yang sepadan, perempuan diharapkan melakukan perannya untuk melengkapi ketidaklengkapan dari laki-laki. Hal ini mengingatkan para Wanita Kristen bagaimana seharusnya mereka berperan melengkapi pasangannya dalam kesetaraan gambar dan rupa Allah. Memang tidak ada superioritas dan inferioritas diantara kedua jenis kelamin tersebut karena mereka diciptakan segambar dan serupa, tetapi ada peran masingmasing yang Allah tetapkan sebagai laki-laki dan perempuan.

\section{Rekomendasi untuk Penelitian Lanjutan}

Penelitian ini dapat dilanjutkan terhadap pembahasan tentang respon Adam (Kej. 2:23-25) tentang repetisi tindakan Allah terhadap penciptaan perempuan dan isu peran laki-laki dan perempuan dalam Kejadian 2:18-25 yang berhubungan secara intertekstual dengan 1 Timotius 2:13-14 maupun keseluruhan surat-surat Paulus.

62 Ibid. 


\section{Kesimpulan}

Kitab Kejadian memberikan uraian khusus tentang manusia pada pasal 2:1822, khususnya mengenai hubungan laki-laki dan perempuan. Dengan menggunakan pendekatan hermeneutik (interpretative design): eksegesis, penulis menemukan bahwa paralelisme repetitif (paralelisme bertangga) dalam kejadian 2:18-22 ("Tuhan Allah berfirman...," "Tuhan Allah membentuk...," Tuhan Allah membuat..." dan "Tuhan Allah menciptakan...") menunjukan peran aktif Allah atas tujuan ciptaanNya kepada manusia. Hal tersebut dapat diperhatikan kembali bagaimana Allah menciptakan seorang perempuan dengan memperhatikan tujuan mula-mula diciptakan manusia pada Kejadian 1: 26-28 sebagai gambar dan rupa Allah untuk menguasai bumi serta ciptaan-ciptaan yang lain. Alhasil, penciptaan laki-laki dan perempuan tidak menunjukan adanya superioritas laki-laki ataupun inferioritas perempuan. Hal tersebut dibuktikan oleh penulis dalam mengartikan penggunaan kata "penolong" dan "sepadan," khususnya maksud kesatuan antara laki-laki dan perempuan menjadi satu daging (Kej. 2:18).

\section{Rujukan}

Agana, Agana-Nsiire. “Is Marriage for All? A Theological Reflection on the Grammar of Genesis 2:18, 24." Asia-Africa Journal of Mission and Ministry 17, no. 3 (2018): 90.

Alexander, Henning. "Males and Females As Equals in Melanesia (An Exegesis of Genesis 2:18-25)." Melanesian Journal of Theology 20, no. 1 (2004): 65.

Archer, Gleason L. Encyclopedia of Bible Difficulties. Edited by Suhadi Yeremia and Subhandiah Tjuk Kaihatu. Malang: Gandum Mas, 2004.

Audirsch, Jeffrey G. "Book Review: Discovering Genesis: Content, Interpretation, Reception." Biblical Theology Bulletin: Journal of Bible and Culture 48, no. 1 (2018): 41-42.

Baden, Joel. “An Unnoted Nuance in Genesis 2:21-22." Vetus Testamentum 69, no. 1 (2019): 167-172.

Bandstra, Barry. Genesis 1-11: A Handbook on The Hebrew Text. Waco, Texas: Baylor University Press, 2008.

Botterweck, G Johannes, and Helmer Ringgren. Theological Dictionary of The Old Testament, Vol. VI. 1990: William B. Eerdmans, 1990.

Botterweck, G Johannes, Helmer Ringgren, and Heinz-Josef Fabry. Theological Dictionary of The Old Testament. Michigan: William B. Eerdman's, 1998.

Brown, Francis, S. R. Driver, and Charles Augustus Briggs. A Hebrew And English Lexicon of the Old Testament. Oxford: Clarendon Press, 1980.

Butar-butar, Grecetinovitria Merliana. "Ezer Kenegdo: Eksistensi Perempuan Dan Perannya Dalam Keluarga." Jurnal Teologi Cultivation 4, no. 1 (2020): 50-51.

Chia, Philip Suciadi. "A Marriage Concept on Genesis 2:21-24 (An Analysis of Latin Vulgate)." Didaskalia 2, no. 1 (2019): 29.

Clarke, Adam. Adam Clarke's Commentary on the Old Testament. New York: Abingdon Press, 1999.

Culver, Robert D. Theological Wordbook of the Old Testament. Chicago: The Moody Bible Institute, 1981.

Driver, G. R. “Theological and Philological Problems in the Old Testament." The 
Journal of Theological Studies 47, no. 1 (1946): 161-162.

Estes, Joel D. "Imperfection in Paradise: Reading Genesis 2 through the Lens of Disability and a Theology of Limits." Horizons in Biblical Theology 38, no. 1 (2016): 1-21.

Freedman, David. "A Power Equal to Man: Translation of Woman as a 'Fit Helpmate' for Man Is Questioned." Biblical Archeology Review 9, no. 1 (1983): 56-58.

Galbraith, Deane. "Review of John H . Walton, The Lost World of Adam and Eve : Genesis 2 - 3 and the Human Origins Debate Related Papers." Journal of the Evangelical Theological Society 58, no. 1 (2015): 168.

Gunawan, Lina. “Kesetaraan Dan Perbedaan Laki-Laki Dan Perempuan: Kritik Terhadap Gerakan Feminisme." Societas 3, no. 2 (2016): 306.

Halawa, Junius. "Pastoral Konseling Psikologi Alkitabiah Seks Sebelum Menikah." Missio Eclesiae 7, no. 2 (2018): 297.

Hamilton, V. P. The Book of Genesis: Chapter 1-17. Grand Rapids: Eerdmans Publishing, 1990.

Harefa, Juliman. "Makna Allah Pencipta Manusia Dan Problematika Arti Kata 'Kita' Di Dalam Kejadian 1:26-27." EPIGRAPHE: Jurnal Teologi dan Pelayanan Kristiani 3, no. 2 (2019): 111-113.

Hastuti, Ruwi. “Pendidikan Agama Kristen Dalam Keluarga Sebagai Pusat Bermisi." Jurnal Antusias 2, no. 4 (2018): 57.

Heri Lim. "MEMAHAMI KISAH PENCIPTAAN MANUSIA DAN ALAM SEMESTA: Sebuah Pendekatan Literer Terhadap Kejadian 1-2." Jurnal Amanat Agung 14, no. 2 (2020): 201-202.

Hiebert, Theodore. "Retranslating Genesis 1-2: Reconnecting Biblical Thought and Contemporary Experience." The Bible Translator 70, no. 3 (2019): 270.

Holladay, William L. Concise Hebrew and Aramic Lexicon. Michigan: Wm. B. Eerdmans Publishing, 1971.

Jamieson, Robert. "The First Book of Moses, Called Genesis." In Jamieson-FaussettBrown Commentary on the Whole Bible, 17. Harrington: Delmarva Publications, 2013.

Keil, C F, and F Delitzsch. Commentary on Genesis. Reprint. Grand Rapids: Eerdmans, $N d, 2000$.

Kidner, F. Derek. Genesis. Chicago: InterVarsity Press, 1967.

Kline, Meredith G. "Kejadian." In Tafsiran Alkitab Masa Kini, Jil. 1, 84. Jakarta: Yayasan Komunikasi Bina Kasih, 1982.

Koehler, Ludwig. Old Testament Theology. Philadelphia: Westminster John Knox Press, 1957.

Koehler, Ludwig, and Walter Baumgartner. Lexicon in Veteris Testamenti Libros. Leiden: Brill, 1958.

Maleachi, Martus Adinugraha, and Hendra Yohanes. "Kehadiran Tuhan Di Tengah Umat-Nya: Dari Penciptaan Ke Penciptaan Yang Baru." Veritas: Jurnal Teologi dan Pelayanan 19, no. 1 (2020): 14.

Martens, Elmer A. Theological Wordbook of the Old Testament. Chicago: The Moody Bible Institute, 1981. 
Mattews, Kenneth A. The New American Commentary: An Exegetical and Theological Exposition of Holy Scripture Genesis 1:11-26, Vol. 1A. Nashville: B\&H Publishing Group, 1996.

McComiskey, Thomas E. Theological Wordbook of the Old Testament. Chicago: The Moody Bible Institute, 1981.

Osborne, Grant R. Hermeneutika Spiritual- Pengantar Komperehensip Bagi Penafsiran ALkitab. Surabaya: Momentum, 2012.

Perangin-angin, Yakub Hendrawan, and Tri Astuti Yeniretnowati. "Keluarga Yang Sehat Dan Kuat Sebagai Profil Keluarga Kristiani." Discreet: Journal Didache of Christian Education 1, no. 1 (2021): 3.

Peterson, Brian Neil. “Does Genesis 2 Support Same-Sex Marriage? An Evangelical Response." Journal of the Evangelical Theological Society 60, no. 4 (2017): 681-696.

Pike, Dana M. “The Latter-Day Saint Reimaging of 'the Breath of Life' (Genesis 2:7)." Byu Studies 56, no. 2 (2017): 73.

Putra, Adi. "Problematika Teks Dan Makna Matius 19: 9 Tentang Perceraian." Missio Ecclesiae 9, no. 2 (2020): 1-16.

Ramantswana, Hulisani. "Humanity Not Pronounced Good: A Re-Reading of Genesis 1:26-31 in Dialogue with Genesis 2-3." Old Testament Essays 26, no. 2 (2013): 437.

Ross, Allen P. “Genesis." In The Bible Knowledge Commentary, 31. Illinois: Victor Books, 1985.

Sama, N. Genesis. Philadelphia: Jewish Publication Society, 1989.

Santoso, Joko. "Penerapan Pondasi Keluarga Bagi Generasi Penerus." Jurnal Ilmiah Religiosity Entity Humanity (JIREH) 2, no. 2 (2020): 173.

Schneider, Tammi J. "In the Beginning and Still Today: Recent Publications on Genesis." Currents in Biblical Research 18, no. 2 (2020): 142-159.

Speiser, E. A. Genesis "Anchor Bible." Garden City: Doubleday, 1964.

Stration, Beverly J. Out of Eden: Reading, Rhetoric, and Ideology in Genesis 2-3. Sheffield: Sheffield Academic Press, 1995.

Thomson, J. G. “The New American Commentary.” Vetus Testamentum 5, no. 2 (1955): 421-435.

Un, Antonius Steven. “Alkitab Menentang Pernikahan Sesama Jenis Kelamin." Verbum Christi 4, no. 1 (2017): 3-4.

Vangemeren, Willem A. New Intertional Dictionary of Old Testament and Exegesis. Michigan, 1997.

Waltke, Bruce K. Genesis: A Commentary. Grand Rapids: Zondervan Publishing, 2001.

- - - "The Creation Account in Genesis 1:1-13." Bibliotheca Sacra 13, no. 2 (1975): 335-337.

- - - "The Role of Women in the Bible." Crux 31, no. 1 (1995): 29-40.

Westermann, Claus. Genesis 1-11: A Continental Commentary. Minneapolis: Fortress Press, 1994.

White, William. Theological Wordbook of the Old Testament, Jil. 2. Chicago: The Moody Bible Institute, 1981.

Zaluchu, Sonny Eli. "Metode Penelitian Di Dalam Manuskrip Jurnal Ilmiah Keagamaan." Jurnal Teologi Berita Hidup 3, no. 2 (2021): 254. 
Jurnal Ilmiah Religiosity Entity Humanity (JIREH)

Vol. 3, No. 2, (Desember, 2021): 107-125

- - - . "Strategi Penelitian Kualitatif Dan Kuantitatif Di Dalam Penelitian Agama." Evangelikal: Jurnal Teologi Injili dan Pembinaan Warga Jemaat 4, no. 1 (2020): 35. 